\title{
Clostridium difficile Infections in Children: Impact of the Diagnostic Method on Infection Rates
}

\author{
Mohammad AlGhounaim, MD; ${ }^{1}$ Yves Longtin, MD; ${ }^{2}$ Milagros Gonzales, MSc; ${ }^{3}$ Joanna Merckx, MD; ${ }^{1,4}$ \\ Nicholas Winters, MSc; ${ }^{3}$ Caroline Quach, MD, MSc ${ }^{1,3,4}$
}

BACKGRound. Polymerase chain reaction (PCR) assays based on the detection of the toxin B gene are replacing enzyme-linked immunosorbent assay (ELISA)-based toxin production detection or cell cytotoxicity assay in most laboratories.

овјестіve. To determine the proportion of pediatric patients diagnosed with Clostridium difficile infection by PCR who would have also been diagnosed by ELISA and to compare the clinical characteristics of PCR+/ELISA+ vs PCR+/ELISA- patients.

метнорs. Using the microbiology laboratory information system, stool samples positive for $C$. difficile by PCR between October 2010 and July 2014 were identified. Using frozen stool specimens, an ELISA for toxin A and B was performed. A retrospective medical chart review was conducted to obtain demographic and clinical data. Duplicate samples were excluded.

RESUlts. A total of 136 PCR-positive samples underwent ELISA testing: 54 (40\%) were positive for toxin A or B. The mean (SD) age of the entire cohort was 8.5 (6.2) years. There was no difference in age, gender, clinical manifestation, previous medical problems, and management between patients positive or negative by ELISA. However, patients positive by ELISA were more likely to have had a recent exposure to antibiotics (67.9\% vs 50\%; crude odds ratio, 2.1 [95\% CI, $1.03-4.28]$ ).

CONCLUSION. In our pediatric population, $60 \%$ of patients with C. difficile diagnosed by PCR had no toxin detectable by ELISA. ELISA-negative patients were less likely to have received an antibiotic recently compared with ELISA-positive patients. These results highlight the need to standardize laboratory criteria for the diagnosis of $C$. difficile infections in children.

Infect Control Hosp Epidemiol 2016;37:1087-1093

Clostridium difficile is an anaerobic spore-forming and toxinproducing bacteria that was initially discovered in 1935 . It was not until 1978 that it was identified as a cause for antibioticassociated diarrhea. ${ }^{1}$ Currently, it is considered to be the most common cause of hospital- and antibiotic-associated diarrhea, with a more severe form causing pseudomembranous colitis. ${ }^{2}$ Recently described strains of $C$. difficile have been associated with increased morbidity and mortality-even in previously healthy individuals. The strain alternatively known as North American pulsed-field gel electrophoresis type 1, restriction endonuclease analysis group $\mathrm{BI}$, and polymerase chain reaction (PCR) ribotype 027 (NAP1/BI/027) is linked to several C. difficile infection (CDI) epidemics in North America, including the Quebec CDI outbreak that peaked between 2001 and 2003. ${ }^{3}$ Asymptomatic colonization of the intestinal tract with $C$. difficile is common, but disease usually occurs only following a disruption in the gastrointestinal microbiota-for example, following antibiotic use, which then allows for C. difficile to proliferate and produce toxins A and B. Toxin A is an enterotoxin responsible for tissue damage and toxin $\mathrm{B}$ is a potent cytotoxin. ${ }^{4-6}$

Early diagnosis and treatment of CDI are important to limit morbidity, healthcare costs, and nosocomial transmission; patients with CDI will require isolation measures, ancillary housekeeping services, and additional antimicrobial therapy. ${ }^{7,8}$ The gold standard tests for the diagnosis of CDI include toxigenic culture and cell culture cytotoxicity assay. Toxigenic culture detects the presence of toxigenic $C$. difficile that has the capacity to produce toxin, whereas culture cytotoxicity assay detects the presence of produced toxin in the stools. However, these techniques are labor-intensive, require expertise, and have a turn-around time that requires more than 48 hours.

Affiliations: 1. Infectious Disease Division, Departments of Pediatrics \& Medical Microbiology, Montreal Children's Hospital of the McGill University Health Center, McGill University, Montreal, Canada; 2. Infection Prevention \& Control Service, Department of Medicine, Jewish General Hospital, McGill University, Montreal, Canada; 3. Research Institute of the McGill University Health Center, Montreal, Canada; 4. Department of Epidemiology, Biostatistics \& Occupational Health, McGill University, Montreal, Canada.

Presented in part: Canadian Association for Clinical Microbiology and Infectious Diseases-Association of Medical Microbiology and Infectious Disease Canada 2015 conference; April 16-18, 2015; Charlottetown, PE, Canada; abstract \#SP15.

Received January 27, 2016; accepted April 29, 2016; electronically published June 6, 2016

(C) 2016 by The Society for Healthcare Epidemiology of America. All rights reserved. 0899-823X/2016/3709-0011. DOI: 10.1017/ice.2016.123 
For that reason, enzyme immunoassays (EIA) were developed to allow for the easy and rapid detection of $C$. difficile toxin. ${ }^{9,10}$ Recently, nucleic acid amplification techniques-such as PCR and loop-mediated isothermal amplification-that are based on the detection of the toxin $B$ gene ( $t c d B)$ have been developed to improve sensitivity over EIA, while maintaining a short turnaround time for the diagnosis of CDI. ${ }^{10,11}$ Several studies showed that PCR had an equivalent sensitivity and specificity (up to $100 \%$ ) compared with toxigenic cultures. ${ }^{12-14}$ However, PCR may not be useful when trying to differentiate carrier status from true CDI. ${ }^{15}$ Moreover, given that clinical manifestations of CDI are milder in children compared with the adult population, ${ }^{16}$ and given the current absence of testing strategies that accurately and optimally diagnose $\mathrm{CDI},{ }^{17}$ we aimed to determine the proportion of pediatric patients diagnosed as having CDI by PCR who would also be diagnosed by EIA, and to compare the clinical characteristics of PCR + /enzyme-linked immunosorbent assay (ELISA) + vs PCR + /ELISA - patients. We also determined the impact of switching from an EIA-based to a PCR-based testing strategy on the proportion of positive samples, as a secondary analysis.

\section{METHODS}

\section{Study Design and Setting}

We performed a retrospective observational cohort study at the Montreal Children's Hospital, a tertiary care facility in Quebec, Canada, with hematopoietic stem cell and solid organ transplant programs. Using the microbiology laboratory information system, a retrospective cohort of patients with diarrhea or change in stool consistency deemed clinically significant by the treating team and with positive $C$. difficile PCR assay between June 2010 and July 2014 was created. Our laboratory protocol rejects stool samples sent for $C$. difficile in infants younger than 6 months. ${ }^{18}$ Stool samples were thus from patients aged 6 months to 18 years from inpatient and outpatient settings. Duplicate stool testing for $C$. difficile - defined as 1 or more tests performed for the same patient within a 14-day window after the initial positive test-were excluded.

\section{Diagnostic Assays}

PCR. All soft or liquid stool samples sent to the microbiology laboratory were tested within 24 hours of reception for toxin $\mathrm{B}$ gene using the $\mathrm{BD}$ GeneOhm $\mathrm{C}$ diff assay, according to the manufacturer's instructions (BD Diagnostics) and the McGill University Health Center laboratory protocol. PCR-based method for the detection of $C$. difficile was implemented in our hospital as a routine test in June 2010. The BD GeneOhm is a real-time PCR that amplifies the toxin B $(t c d B)$ gene from $C$. difficile with fluorogenic target-specific hybridization probes for the identification of amplified target DNA. An internal control was employed and interpreted using the SmartCycler instrument (Cepheid). Results are reported as positive, negative, or indeterminate-in which case a repeated sample is requested. After the procedure, all stool samples were routinely stored in a $-20^{\circ} \mathrm{C}$ non-frost-free freezer.

ELISA. C. difficile TOX A/B II (TechLab) was performed a posteriori on all available samples in a single batch to only thaw samples once. Toxin-detecting antibodies consisted of a mixture of toxin A monoclonal mouse antibody and toxin B polyclonal goat antibody. To perform the test, stool samples were thawed and diluted. The supernatants from stool suspensions were collected and placed in 96-well plates according to the manufacturer's instructions. An optical density of 0.8 or greater was considered positive.

Clinical characteristics. Using a piloted case report form, a medical chart review was performed to extract patients' demographic characteristics, clinical characteristics, and laboratory data. Data collected included recent antibiotic use, clinical manifestations of CDI (abdominal pain, frequency of diarrhea, leukocytosis, fever, elevated C-reactive protein, elevated erythrocyte sedimentation rate, lactic acidosis, elevated stool leukocytes, and presence of blood in the stool), development of complications (intensive care unit admission, shock, or colectomy), management of CDI, and presence of comorbidities or CDI risk factors (Table 1). Targeted CDI risk factors included the presence of inflammatory bowel disease (IBD), malignant tumor, gastric acid suppression medication (either proton-pump inhibitor or histamine-2 inhibitor), immunosuppressive agents, feeding device, cystic fibrosis, Hirschprung disease, immunodeficiency, and bone marrow transplant. Also, the total of $C$. difficile episodes for each patient was obtained up to the time of medical chart review.

Statistical analysis. We used summary statistics to describe clinical characteristics of patients who were positive for C. difficile by both PCR and ELISA with those who were positive only by PCR and used $\chi^{2}$ tests to compare proportions. Continuous variables were compared using the $t$ test. Multivariable analysis was performed on crude odds ratios to adjust for age category ( $<5$ years or $\geq 5$ years), gender, and CDI risk factors (healthy, malignant tumor, immunosuppressive agents, gastric acid suppressive agents, feeding device, bone marrow transplant, and IBD). Statistical analyses were performed using SAS, version 9.3 (SAS Institute), and $\mathrm{R}$, version 3.1.1. A 2-tailed $P \leq .05$ was considered statistically significant.

Ethical considerations. This study was approved by the Montreal Children's Hospital Research Ethics Board.

\section{RESULT S}

During the study period, 310 consecutive stool samples tested positive for $t c d B$ gene by PCR. Of those, 154 samples were retrieved from the microbiology laboratory freezer. A larger proportion of samples obtained before 2012 was missing, whereas most of the samples collected in 2014 were retrieved (Table 2). When comparing missing specimens with those that were found, the same proportion of samples in both categories 
table 1. Demographic and Clinical Characteristics of 136 Patients With Clostridium difficile Detected by PCR, Montreal Children Hospital, Canada, 2010-2014

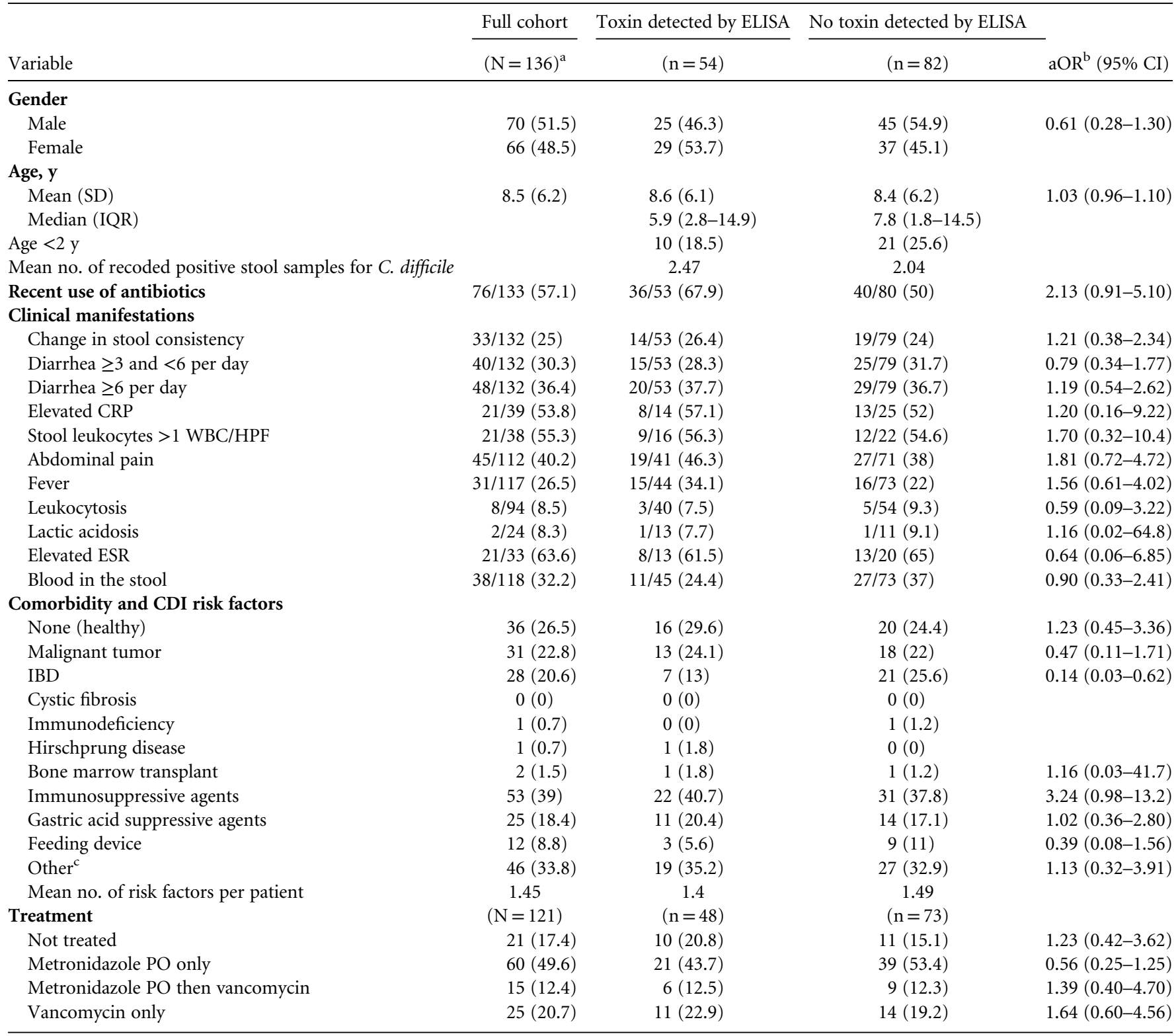

NOTE. Data are no. (\%) of patients unless otherwise indicated. aOR, adjusted odds ratio; CDI, Clostridium difficile infection; CRP, C-reactive protein; ELISA, enzyme-linked immunosorbent assay; ESR, erythrocyte sedimentation rate; HPF, high-power field; IBD, inflammatory bowel disease; IQR, interquartile range; PCR, polymerase chain reaction; PO, per os (by mouth); WBC, white blood cells.

${ }^{\mathrm{a}}$ Denominator as in heading, unless otherwise indicated.

${ }^{\mathrm{b}}$ Adjusted for age category (older or younger than 5 years), gender, and CDI risk factors (healthy, malignant tumor, immunosuppressive agents, gastric acid suppressive agents, feeding device, bone marrow transplant, and IBD).

${ }^{\mathrm{c}} 7$ congenital heart disease, 7 immediate postsurgical period (appendectomy, posterior spinal fusion, ureteric implantation), 4 neurologic disease, 3 post-renal transplant, 3 hepatopancreaticobiliary disorders, 3 genetic disorders (trisomy 21, cri-du-chat), 2 chronic ear and sinus infection, 2 chronic hepatosplenic candidiasis, 18 miscellaneous.

came from ambulatory or inpatient settings (Table 3). In addition, the clinical background was comparable in both groups. Among the samples retrieved, 17 were excluded because they were duplicates and 1 was excluded because the patient was never evaluated in our institution (sold service) (Figure 1). Figure 2 illustrates the proportion of stool specimens that tested positive for $C$. difficile by month during the 13 months prior to PCR implementation and the 50 months 
TABLE 2. Proportion of Specimens Found to Total Samples in the Microbiology Laboratory Database

\begin{tabular}{lc}
\hline Year & Samples found, \% \\
\hline 2010 & 2.1 \\
2011 & 33.7 \\
2012 & 47.9 \\
2013 & 52.6 \\
$2014^{*}$ & 72.4 \\
\hline
\end{tabular}

${ }^{\star}$ Until July 2014 .

TABLE 3. Characteristics of Patients With Lost vs Retrieved Specimens

\begin{tabular}{lccc}
\hline & $\begin{array}{c}\text { Specimens } \\
\text { retrieved N }(\%)\end{array}$ & $\begin{array}{c}\text { Specimens } \\
\text { lost N (\%) }\end{array}$ & $P$ value \\
\hline Clinical setting & $63(40.9)$ & $59(37.8)$ & .77 \\
$\quad$ Inpatient & $49(31.8)$ & $49(31.4)$ & \\
Outpatient & $42(27.2)$ & $48(30.8)$ & \\
Emergency department & & & \\
Clinical background & $39(25.3)$ & $43(27.6)$ & .65 \\
Healthy & $35(22.7)$ & $32(20.5)$ & .63 \\
Malignant tumor & $34(22.1)$ & $35(22.4)$ & .94 \\
IBD & $0(0)$ & $0(0)$ & $\mathrm{NA}$ \\
Cystic fibrosis & $1(0.6)$ & $0(0)$ & $\mathrm{NA}$ \\
Immunodeficiency & $1(0.6)$ & $0(0)$ & $\mathrm{NA}$ \\
Hirschprung disease & $3(1.9)$ & $4(2.6)$ & $>.99$ \\
Bone marrow transplant & $53(34.4)$ & $51(32.7)$ & .75 \\
Immunosuppressing & & & \\
$\quad$ agents & $25(16.2)$ & $15(9.6)$ & .08 \\
Acid suppressing agents & $12(7.8)$ & $10(6.4)$ & .64 \\
Feeding device & $52(33.8)$ & $43(27.6)$ & .23 \\
Other & & 156 & \\
Total & 154 & & \\
\hline
\end{tabular}

NOTE. IBD, inflammatory bowel disease.

${ }^{a}$ Congenital heart disease, immediate postsurgical period, neurologic disease, post-renal transplant, hepatopancreaticobiliary disorders, genetic disorders and syndromes, chronic sinopulmonary infections, chronic fungal infections, chronic kidney diseases, and renal transplant.

following PCR implementation. The switch from EIA to PCR was associated with an increase in the proportion of positive samples, from $5.8 \%$ to $11.3 \%(P=.003)$.

Of the 136 PCR-positive samples that were tested by EIA, fewer than half (54 [40\%]) were positive for toxins A or B. The population's mean age was 8.5 years and approximately half of the sample were boys (Table 1). There was no difference in the mean age of EIA-positive and EIA-negative cases. Although not statistically significant, there was a trend toward having younger patients $(<2$ years of age $)$ in the EIA-negative group compared with EIA-positive patients: $25.6 \%$ vs $18.5 \%$ $(P=.33)$. There was also a trend toward fewer lifetime C. difficile recurrence in the EIA-negative group: $23.1 \%$ had more than 3 documented CDIs compared with $33.3 \%$ in the EIA-positive group $(P=.19)$.

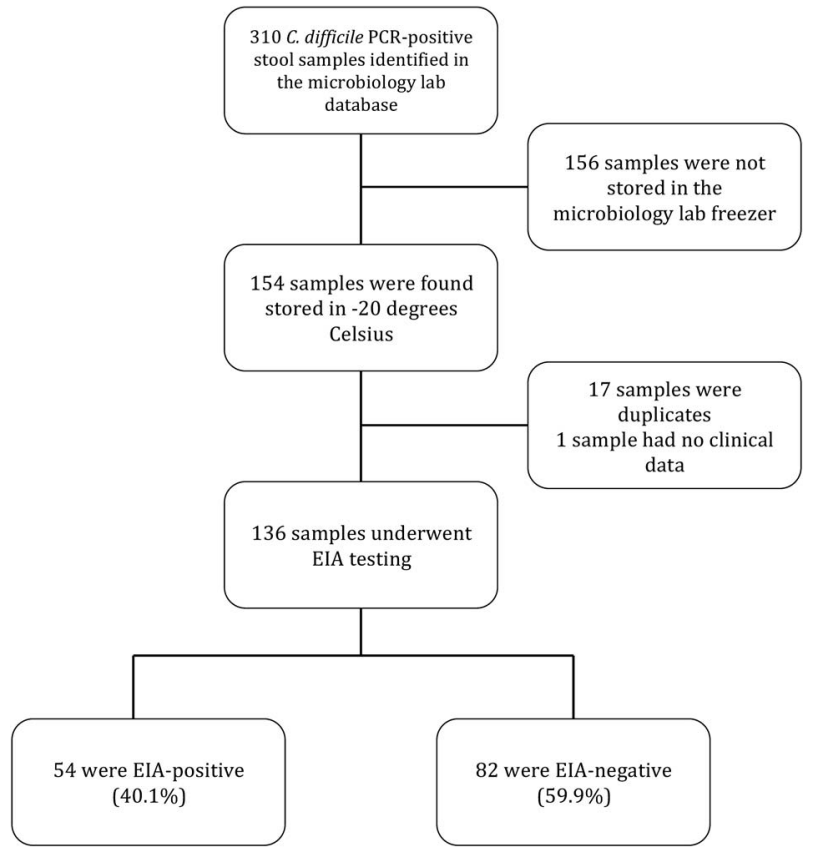

FIGURE 1. Flowchart of specimens tested and results. C. difficile, Clostridium difficile; EIA, enzyme immunoassay; PCR, polymerase chain reaction.

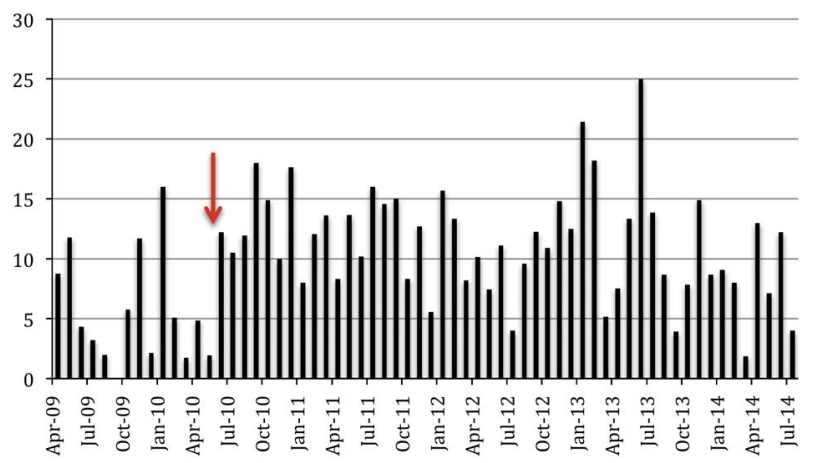

FIGURE 2. Proportion of stool samples that were positive for Clostridium difficile at the Montreal Children's Hospital, by month (April 1, 2009, to August 1, 2014). The arrow indicates when polymerase chain reaction testing for $C$. difficile was implemented.

There was no significant difference in terms of clinical manifestations of CDI and underlying comorbidities between the EIA-positive and EIA-negative cases, looking at the crude and the adjusted odds ratio (OR). EIA-positive patients were more likely to have been recently exposed to antibiotics: $67.9 \%$ of EIA-positive compared with $50 \%$ of EIA-negative (crude OR, 2.1 [95\% CI, 1.03-4.28]). However, this did not remain statistically significant when the OR was adjusted for CDI risk factors (adjusted OR, 2.13 [95\% CI, 0.91-5.10]), likely due to lack of power. This difference was not noted for any specific antimicrobial classes. There were fewer patients with IBD in the EIA-positive group compared with the 
EIA-negative group ( $13 \%$ vs $25.6 \%$; adjusted OR, 0.36 [95\% CI, 0.12-0.96]). There were no significant differences in the treatment choice between the two groups. No complications related to CDI were identified.

\section{I S C U S S I O N}

In our study, only $40 \%$ of patients with a diagnosis of CDI by PCR had a toxin-producing $C$. difficile detectable by EIA. PCR detects the presence of the toxin $B$ gene but not necessarily toxin production. This means that many patients diagnosed by PCR may in fact not have a real CDI but rather another cause for their diarrheal episode. Unlike other studies, ${ }^{19}$ we were not able to demonstrate a statistically significant difference in clinical manifestations between EIA-positive and EIA-negative patients. The 2 groups were similar in their presenting symptoms and management. Upon initial analysis, the absence of difference in the 2 groups' clinical manifestations was believed to be partly attributed to a confounding effect of patients with IBD or alternate diagnoses for diarrhea that were not the focus of this study. Patients with IBD can present with symptoms similar to CDI and hence carriers may be misclassified as having CDI. However, no significant difference in the OR was noted when patients with IBD were excluded from the analysis. It is also possible that the small sample size did not allow for differences to be identified.

The Montreal Children's Hospital healthcare-associated infections surveillance program noticed a slight increase in the incidence of CDI in the year following the implementation of PCR for C. difficile. Our hospital healthcare-associated annual CDI rate was 1.1 cases/10,000 patient-days in 2009-2010 (April 2009 to March 2010) and increased to a pooled mean rate of 3.39 cases/10,000 patient-days from April 2010 to March 2015. Even though the number of positive cases was comparable with those of the previous years, the highest peak was seen after the introduction of PCR in June 2010 and this finding was similar in both the outpatient and inpatient populations. $^{20,21}$

Adult and pediatric centers that implemented PCR-based assays for the detection of $C$. difficile in replacement of EIA noticed an increase in the proportion of positive $C$. difficile tests by 2 - to 10 -fold. ${ }^{22-24}$ For instance, Luna et al ${ }^{22}$ reported an increase in the proportion of $C$. difficile positivity from an average of $8 \%$ to $16.2 \%$ after switching from EIA to PCR. We similarly show that switching from ELISA to PCR increased the number of identified cases by more than 2 -fold. This finding is consistent with other studies that compared PCR with toxin detection in the diagnosis of CDI. It is unclear whether this increase in CDI was due only to the increased sensitivity of the assay and decreased specificity for clinical disease, to a change in circulating strains, or to an indication bias where hospitals in areas with increasing CDI incidence due to outbreaks decided to implement the test. ${ }^{22,24}$

Polage et $\mathrm{al}^{25}$ documented that, in adults, PCR has a positive predictive value of $44.7 \%$ compared with EIA. The increase in the number of cases cannot be explained solely by the difference in performance characteristics of the 2 tests: the sensitivity (68\%-90\% for EIA vs $88 \%-100 \%$ for PCR) and specificity ( $95.3 \%-99 \%$ for EIA vs $92.6 \%-98.4 \%$ for PCR) of the 2 tests are comparable. ${ }^{12-14,26,27}$ The sudden increase in the incidence of CDI following the implementation of PCR could be partly explained by the fact that PCR detects toxin genes but cannot determine whether the organism is actively producing toxin. For that reason, some studies concluded that PCR is unreliable in differentiating CDI cases from asymptomatic carriers of a potentially toxigenic organism. ${ }^{15}$ Planche et $\mathrm{al}^{28}$ documented that CDI severity and related mortality was higher in patients with positive toxin assay compared with patients who were positive by toxigenic culture but toxin assay negative. More false-positive results may be seen with PCR compared with toxin detection methods. ${ }^{25}$ This is supported by the fact that in adult populations, the complication rate in patients with CDI is $40 \%-50 \%$ higher if they were diagnosed with EIA or cytotoxicity assay compared with PCR. ${ }^{23,25}$ In pediatrics, the complication rates are significantly lower compared with adults. ${ }^{16}$

Toxigenic C. difficile carriage has been documented in healthy adults with a rate that was reported to be as high as $14 \%$ in hospitalized patients. ${ }^{29,30}$ The asymptomatic carriage rate in children, especially in those younger than 3 years, was found to be even higher than in adults. Rousseau et $\mathrm{a}^{31}$ demonstrated in a small cohort that almost $40 \%$ of infants were carriers of toxigenic $C$. difficile by the age of 6 months. A study by Matsuki et $\mathrm{a}^{32}$ showed a carriage rate of $48 \%$ for children younger than 5 years, with the highest carriage rate $(80 \%-100 \%)$ being in infants. In a case-control study that looked for causes of diarrhea in children, the proportion of $C$. difficile positives was higher in controls compared with cases. ${ }^{33}$ Our study's objective was not to document carriage rate.

The effect of single or multiple freeze-thaw cycles on the performance characteristics of the EIA have not been well studied. A study by Lyerly ${ }^{34}$ concluded that multiple freezethaw cycles could lead to toxin degradation. A similar finding was shown by Freeman and Wilcox ${ }^{35}$ where the toxin titer dropped from $1 \times 10^{6}$ toxin units to $1 \times 10^{1}$ toxin units after 56 days with multiple freeze-thaw cycles. However, this is unlikely to account for the current study result because only 1 freeze-thaw cycle was performed. In a study by Arrow et al, ${ }^{36}$ the immunogenic effect of $C$. difficile was preserved, with a superiority of EIA over toxigenic cultures, after a single freeze-thaw cycle. Also, Sharp et $\mathrm{al}^{37}$ showed that a glutamate dehydrogenase and A/B Toxin Combination test remained positive in 26 of 27 samples after a single freeze-thaw cycle.

To our knowledge, this is the first study that aimed to evaluate the clinical implications of implementing PCR for the diagnosis of CDI in children. However, it has its limitations. The major limitation of this study is its retrospective nature. Because it was limited to information written in the medical chart, it is possible that clinical manifestations were not well documented. However, it is likely that severe manifestations 
would have been recorded. This could explain why it failed to show a significant difference between EIA-positive and EIA-negative patients in terms of clinical characteristics. Another limitation is that it was not possible to perform toxigenic cultures to determine definitely whether PCRpositive but EIA-negative samples were true- or false-positive results. Despite all that, one can presume that PCR is likely overestimating the rate of CDI, at least in the pediatric population. The difference between the 2 groups cannot be explained merely by the difference between the tests' performance. For that reason, some authors suggested validating PCR testing by developing a quantitative PCR or adding another step in the diagnostic process, which would include either a test that detects functional toxins or a test for a fecal marker of inflammation. ${ }^{15,38-40}$

\section{ACKNOWLEDGMENTS}

Financial support. Alera (supply of ELISA kits).

Potential conflicts of interest. C.Q. reports that she has received funding from GlaxoSmithKline, Pfizer, Sage, and AbbVie (all for research grant or support for unrelated research projects). Y.L. reports that he has acted as a consultant for AMG Medical and Oxypharm and received funding from GenePOC. All other authors report no conflicts of interest relevant to this article.

Address correspondence to Caroline Quach, MD, MSc, McGill University Health Center, 1001 Decarie Blvd, Ste EE05-1954, Montreal (QC) H4A 3J1, Canada (caroline.quach@mcgill.ca).

\section{REFERENCES}

1. Bartlett JG. Antibiotic-associated pseudomembranous colitis. Rev Infect Dis 1979;1:530-539.

2. Wilkins TD, Lyerly DM. Clostridium difficile testing: after 20 years, still challenging. J Clin Microbiol 2003;41:531-534.

3. O'Donoghue C, Kyne L. Update on Clostridium difficile infection. Curr Opin Gastroenterol 2011;27:38-47.

4. Guilbault C, Labbe AC, Poirier L, Busque L, Beliveau C, Laverdiere M. Development and evaluation of a PCR method for detection of the Clostridium difficile toxin B gene in stool specimens. J Clin Microbiol 2002;40:2288-2290.

5. Hatheway CL. Toxigenic Clostridia. Clin Microbiol Rev 1990;3: 66-98.

6. Taur Y, Pamer EG. Harnessing microbiota to kill a pathogen: fixing the microbiota to treat Clostridium difficile infections. Nat Med 2014;20:246-247.

7. Dubberke ER, Olsen MA. Burden of Clostridium difficile on the healthcare system. Clin Infect Dis 2012;55:S88-S92.

8. Dubberke ER, Reske KA, Olsen MA, McDonald LC, Fraser VJ. Short- and long-term attributable costs of Clostridium difficileassociated disease in nonsurgical inpatients. Clin Infect Dis 2008; 46:497-504.

9. Delmee M, Van Broeck J, Simon A, Janssens M, Avesani V. Laboratory diagnosis of Clostridium difficile-associated diarrhoea: a plea for culture. J Med Microbiol 2005;54:187-191.

10. van den Berg RJ, Bruijnesteijn van Coppenraet LS, Gerritsen HJ, Endtz HP, van der Vorm ER, Kuijper EJ. Prospective multicenter evaluation of a new immunoassay and real-time PCR for rapid diagnosis of Clostridium difficile-associated diarrhea in hospitalized patients. J Clin Microbiol 2005;43:5338-5340.

11. van den Berg RJ, Bakker D, Kuijper EJ. Diagnosis of Clostridium difficile infection using real-time PCR. Methods Mol Biol 2013; 943:247-256.

12. Peterson LR, Manson RU, Paule SM, et al. Detection of toxigenic Clostridium difficile in stool samples by real-time polymerase chain reaction for the diagnosis of $C$. difficile-associated diarrhea. Clin Infect Dis 2007;45:1152-1160.

13. van den Berg RJ, Vaessen N, Endtz HP, Schulin T, van der Vorm ER, Kuijper EJ. Evaluation of real-time PCR and conventional diagnostic methods for the detection of Clostridium difficile-associated diarrhoea in a prospective multicentre study. J Med Microbiol 2007;56:36-42.

14. Samra Z, Luzon A, Bishara J. Evaluation of two rapid immunochromatography tests for the detection of Clostridium difficile toxins. Dig Dis Sci 2008;53:1876-1879.

15. Dupont HL. Diagnosis and management of Clostridium difficile infection. Clin Gastroenterol Hepatol 2013;11:1216-1223.

16. Morinville V, McDonald J. Clostridium difficile-associated diarrhea in 200 Canadian children. Can J Gastroenterol 2005;19:497-501.

17. Cohen SH, Gerding DN, Johnson S, et al. Clinical practice guidelines for Clostridium difficile infection in adults: 2010 update by the Society for Healthcare Epidemiology of America (SHEA) and the Infectious Diseases Society of America (IDSA). Infect Control Hosp Epidemiol 2010;31:431-455.

18. Gerding DN, Johnson S, Peterson LR, Mulligan ME, Silva J Jr. Clostridium difficile-associated diarrhea and colitis. Infect Control Hosp Epidemiol 1995;16:459-477.

19. Patel H, Randhawa J, Nanavati S, Marton LR, Baddoura WJ, DeBari VA. Laboratory and clinical features of EIA toxin-positive and EIA toxin-negative community-acquired Clostridium difficile infection. Ann Clin Lab Sci 2015;45:333-339.

20. Gonzales M, Quach C, Perpete C, Moore D. Infection Control Service Annual Report (2012-2013). Montreal: Montreal Children's Hospital; 2013.

21. Quach C, Perpete C, Lacharite S. Infection Control Service Annual Report (2010-2011). Montreal: Montreal Children's Hospital; 2011.

22. Luna RA, Boyanton BL Jr, Mehta S, et al. Rapid stool-based diagnosis of Clostridium difficile infection by real-time PCR in a children's hospital. J Clin Microbiol 2011;49:851-857.

23. Longtin Y, Trottier S, Brochu G, et al. Impact of the type of diagnostic assay on Clostridium difficile infection and complication rates in a mandatory reporting program. Clin Infect Dis 2013;56:67-73.

24. Khanna S, Baddour LM, Huskins WC, et al. The epidemiology of Clostridium difficile infection in children: a populationbased study. Clin Infect Dis 2013;56:1401-1406.

25. Polage CR, Gyorke CE, Kennedy MA, et al. Overdiagnosis of Clostridium difficile infection in the molecular test era. JAMA Intern Med 2015:1-10.

26. Snell H, Ramos M, Longo S, John M, Hussain Z. Performance of the Techlab C. Diff Chek-60 enzyme immunoassay (EIA) in combination with the $C$. difficile Tox A/B II EIA kit, the Triage C. difficile Panel immunoassay, and a cytotoxin assay for diagnosis of Clostridium difficile-associated diarrhea. J Clin Microbiol 2004;42:4863-4865.

27. Eastwood K, Else P, Charlett A, Wilcox M. Comparison of nine commercially available Clostridium difficile toxin detection assays, 
a real-time PCR assay for $C$. difficile tcdB, and a glutamate dehydrogenase detection assay to cytotoxin testing and cytotoxigenic culture methods. J Clin Microbiol 2009;47:3211-3217.

28. Planche TD, Davies KA, Coen PG, et al. Differences in outcome according to Clostridium difficile testing method: a prospective multicentre diagnostic validation study of $C$. difficile infection. Lancet Infect Dis 2013;13:936-945.

29. Shim JK, Johnson S, Samore MH, Bliss DZ, Gerding DN. Primary symptomless colonisation by Clostridium difficile and decreased risk of subsequent diarrhoea. Lancet 1998;351:633-636.

30. Kyne L, Warny M, Qamar A, Kelly CP. Asymptomatic carriage of Clostridium difficile and serum levels of IGG antibody against toxin A. N Engl J Med 2000;342:390-397.

31. Rousseau C, Poilane I, De Pontual L, Maherault AC, Le Monnier A, Collignon A. Clostridium difficile carriage in healthy infants in the community: a potential reservoir for pathogenic strains. Clin Infect Dis 2012;55:1209-1215.

32. Matsuki S, Ozaki E, Shozu M, et al. Colonization by Clostridium difficile of neonates in a hospital, and infants and children in three day-care facilities of Kanazawa, Japan. Int Microbiol 2005;8:43-48.

33. Denno DM, Shaikh N, Stapp JR, et al. Diarrhea etiology in a pediatric emergency department: a case control study. Clin Infect Dis 2012;55:897-904.
34. Lyerly D. The toxins of Clostridium difficile and their detection in the clinical laboratory. Clin Microbiol Updates 1992;4:1-6.

35. Freeman J, Wilcox MH. The effects of storage conditions on viability of Clostridium difficile vegetative cells and spores and toxin activity in human faeces. J Clin Pathol 2003;56: 126-128.

36. Arrow SA, Croese L, Bowman RA, Riley TV. Evaluation of three commercial enzyme immunoassay kits for detecting faecal Clostridium difficile toxins. J Clin Pathol 1994;47:954-956.

37. Sharp SE, Ruden LO, Pohl JC, Hatcher PA, Jayne LM, Ivie WM. Evaluation of the C. Diff Quik Chek Complete assay, a new glutamate dehydrogenase and A/B toxin combination lateral flow assay for use in rapid, simple diagnosis of Clostridium difficile disease. J Clin Microbiol 2010;48:2082-2086.

38. Vaishnavi C, Bhasin D, Kochhar R, Singh K. Clostridium difficile toxin and faecal lactoferrin assays in adult patients. Microbes Infect 2000;2:1827-1830.

39. El Feghaly RE, Stauber JL, Tarr PI, Haslam DB. Intestinal inflammatory biomarkers and outcome in pediatric Clostridium difficile infections. J Pediatr 2013;163:1697-1704.e2.

40. Dubberke ER, Burnham CD. Diagnosis of Clostridium difficile infection: treat the patient, not the test. JAMA Intern Med 2015:1-2. 